\title{
Renal cell carcinoma with metachronous metastasis to the contralateral adrenal gland and urinary bladder: A case report
}

\author{
KAI WANG ${ }^{1}$, JUNKAI WANG $^{2}$, JI SUN $^{1}$, DACHUAN ZHONG $^{1}$, SHENGCHENG TAI $^{1}$, DANFENG XU $^{2}$ and YI FAN ${ }^{1}$ \\ ${ }^{1}$ Department of Urology, Zhejiang Xiaoshan Hospital, Hangzhou, Zhejiang 311202; ${ }^{2}$ Department of Urology, \\ Shanghai Changzheng Hospital, Second Military Medical University, Shanghai 200003, P.R. China
}

Received November 23, 2014; Accepted July 30, 2015

DOI: $10.3892 / \mathrm{ol} .2015 .3722$

\begin{abstract}
The adrenal gland and urinary bladder are rare localizations of metastases of renal cell carcinoma (RCC). In the present study, a case of metastasis to the contralateral adrenal gland and urinary bladder of clear cell-type RCC (ccRCC) in the left kidney is reported in a male who had undergone left radical nephrectomy at 55 years of age. Computed tomography $(\mathrm{CT})$ revealed a mass in the right adrenal gland 5 years following surgery, and type-B ultrasound demonstrated a $1.0-\mathrm{cm}$ solid space-occupying lesion in the right wall of the bladder. Consequently, laparoscopic right adrenalectomy and transurethral resection of the bladder tumor were performed. Furthermore, based on histopathological examination and immunohistochemical staining, the patient was pathologically diagnosed with contralateral adrenal gland and urinary bladder metastasis of ccRCC. CT performed at the 1-year follow-up detected multiple solid space-occupying lesions in the right kidney. Therefore, the patient was treated with sunitinib targeted therapy. To date, the patient is generally in good condition, without evident drug side effects or complaints of discomfort.
\end{abstract}

\section{Introduction}

Renal cell carcinoma (RCC) accounts for 3\% of all adult malignancies and $85 \%$ of all primary renal tumors; RCC is the third most common type of urological cancer, after prostate and bladder cancer (1). Currently, the incidence of RCC is rising, due to the increased number of incidental findings by imaging tests. In 2013, it was estimated that there will be 65,150 new cases of kidney and renal pelvis cancers and 13,680 cancer-related mortalities in the United States (2). It has been reported that the five-year cancer-related survival

Correspondence to: Professor Yi Fan, Department of Urology, Zhejiang Xiaoshan Hospital, 728 North Yucai Road, Xiaoshan, Hangzhou, Zhejiang 311202, P.R. China

E-mail: fanyi@zjxsh.com

Key words: renal cell carcinoma, adrenal gland, urinary bladder, adrenalectomy rate was $90.4 \%$ for patients with localized disease, $62.3 \%$ for patients with regional lymph nodes metastasis, $10.4 \%$ for patients with distal metastasis (3). Of the newly diagnosed cases of RCC, $\sim 25-50 \%$ will develop metastatic disease subsequent to surgical resection of the primary renal mass (4). RCC frequently metastasizes to distal organs, such as lungs, abdomen, bones and brain. Contralateral adrenal gland and urinary bladder metastasis are rare, and have been previously described case reports $(5,6)$. To the best of our knowledge, RCC with metachronous metastasis to the contralateral adrenal and bladder has not been reported. For treatment of metastatic renal cell carcinoma, complete resection of metastases or not remains contraversial (7). Cancer-specific survival rates between metastases resected and non-resected populations have previously been reported and prolonged survival was observed with metastases resection $(8,9)$. In the present study, an unusual case of clear cell-type RCC (ccRCC) with metachronous metastasis to the contralateral adrenal gland and urinary bladder 5 years following nephrectomy is reported.

\section{Case report}

A 55-year-old male was referred to the Department of Urology of the Zhejiang Xiaoshan Hospital (Hangzhou, China) in October 2005, exhibiting a case of left-kidney RCC. Radical nephrectomy was performed (Fig. 1), and the postoperative pathology findings confirmed cc-type and $\mathrm{pT}_{1 \mathrm{a}} \mathrm{N}_{0} \mathrm{M}_{0}$, according to the American Joint Committee on Cancer 2009 cancer staging (Fig. 2) (10). No recurrence was observed during the follow-up period until November 2010, when upper abdominal computed tomography (CT) revealed a 40x45-mm enhanced mass in the right adrenal gland (Fig. 3). Subsequent laboratory tests demonstrated the tumor to be hormonally inactive. In addition, type-B ultrasound revealed a 1.0-cm solid space-occupying lesion in the right wall of the bladder. Thoracic CT and bone scan did not identify any other metastases.

Following hospitalization, laparoscopic right adrenalectomy and transurethral resection of the bladder tumor were performed. Histopathological examination of the resected tissues confirmed cc carcinoma, which was identical to that of the left renal tumor previously experienced by the patient (Figs. 4-7). CT and intravesical instillation chemotherapy were 


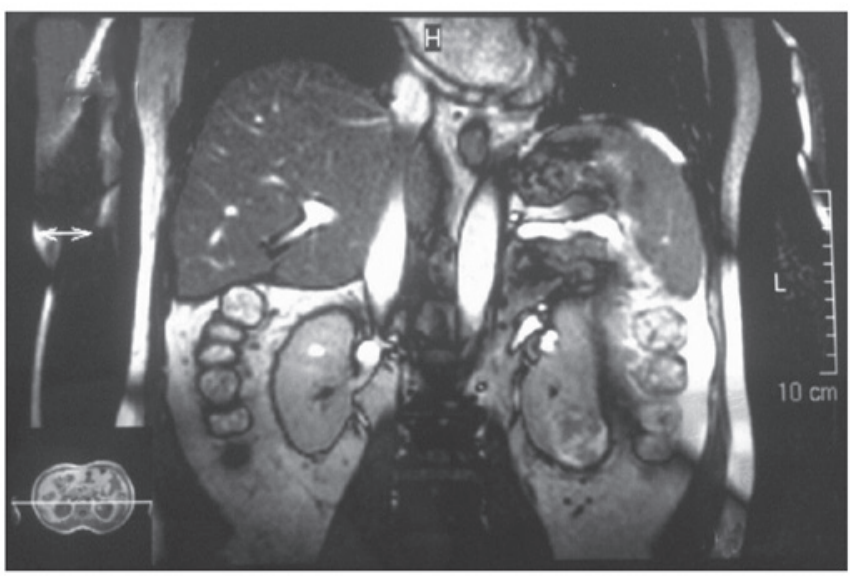

Figure 1. Preoperative magnetic resonance imaging demonstrated the left renal lesion to be located in the lower pole.

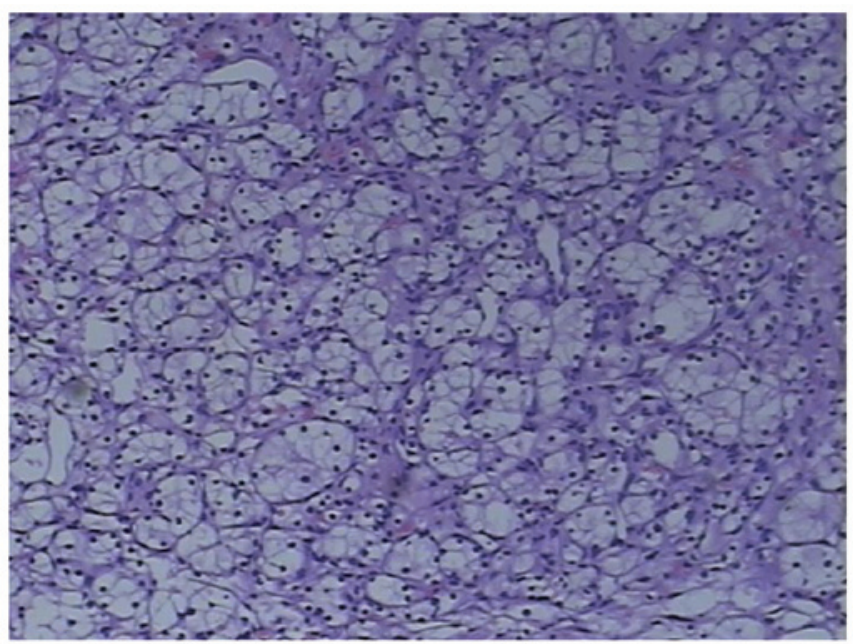

Figure 2. Hematoxylin-eosin staining of the right renal specimen revealed clear renal cell carcinoma. Formalin-fixed paraffin-embedded renal specimen were cut into $4-\mu \mathrm{m}$ sections and stained with hematoxylin-eosin to evaluate the cell pattern. The sections were scanned under a light microscope and images were captured at a magnification of $\times 200$. The lesional cells exhibited a nested growth pattern, in a background of delicate, arborizing vasculature.

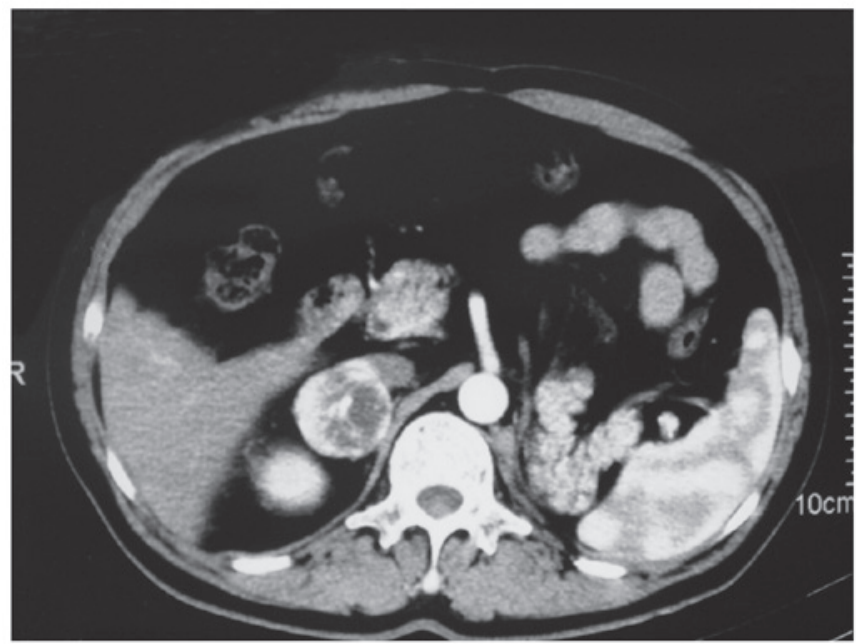

Figure 3. Computed tomography identified a $40 \times 45-\mathrm{mm}$ enhanced mass in the right adrenal gland.

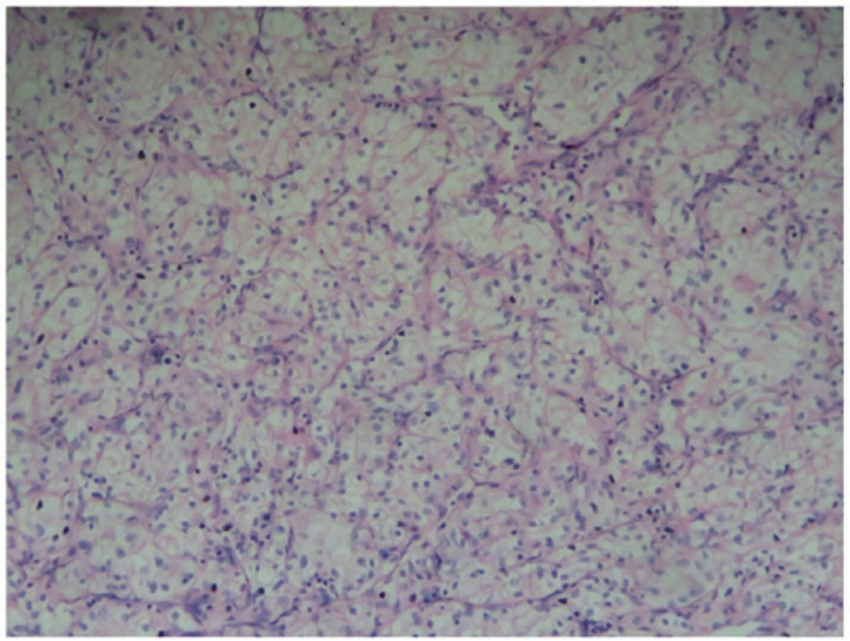

Figure 4. Hematoxylin-eosin stain of the right adrenal gland specimen revealed metastatic clear cell renal cell carcinoma replacing normal adrenal tissue $(\times 200)$.

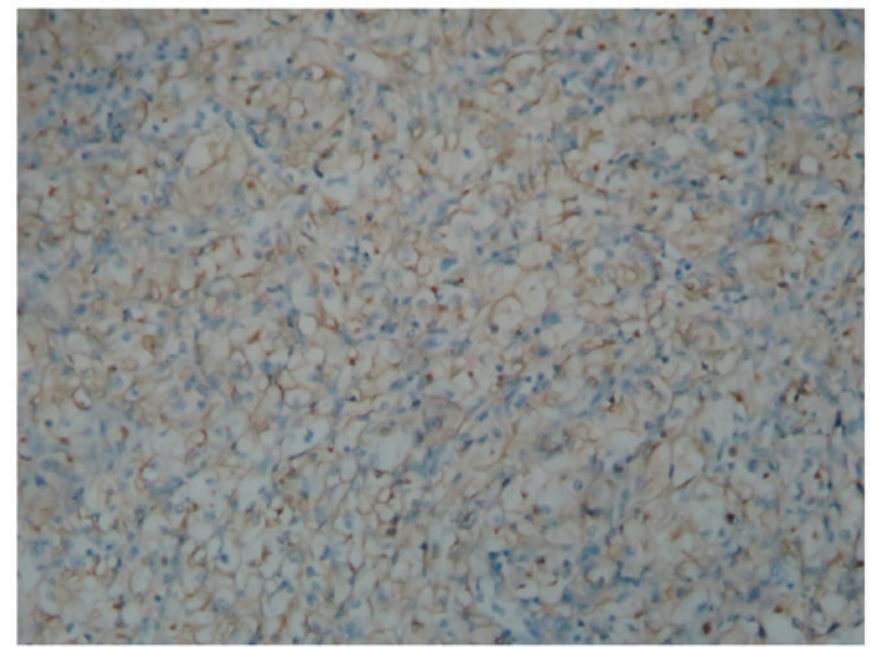

Figure 5. The slides were examined under light microscope at a magnification of $\times 200$. The infiltrated tumor cells in the right adrenal gland were positive for CD10.

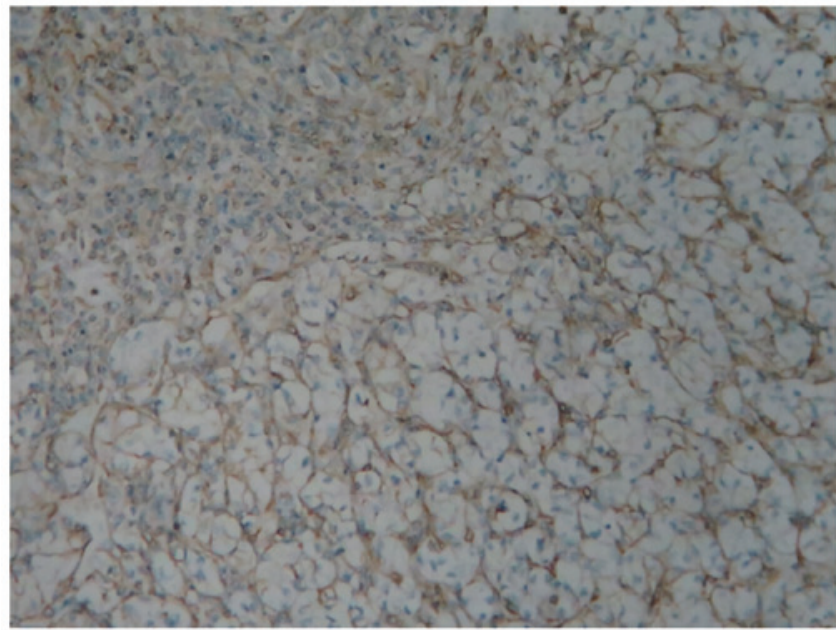

Figure 6 . The sides were examined under light microscope at a magnification of $\times 200$. The infiltrated tumor cells in the right adrenal gland were positive for vimentin. 


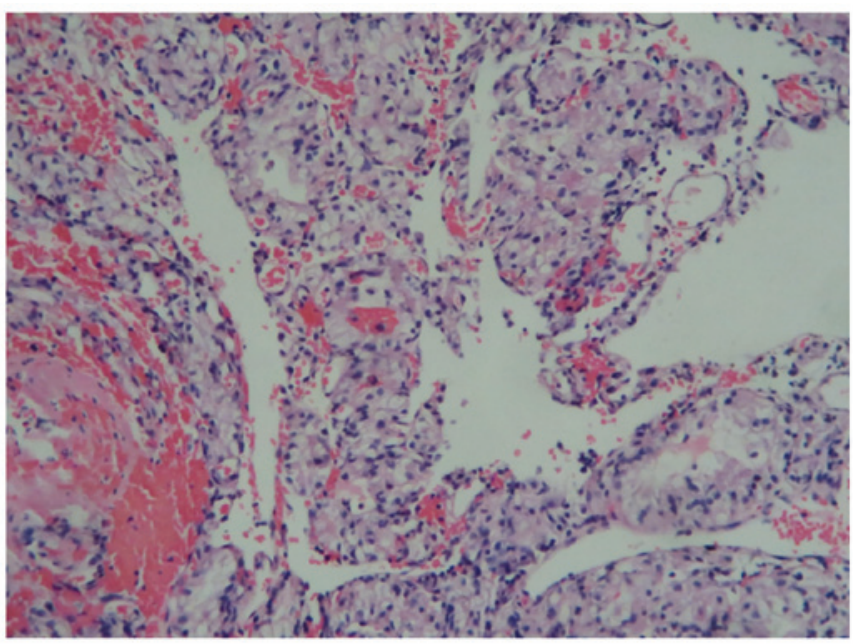

Figure 7. Hematoxylin-eosin staining of the urinary bladder revealed metastatic renal cell carcinoma. The tumor shows a clear cell pattern that is identical, histologically, to the previous renal cell carcinoma. Original magnification, $\times 200$.

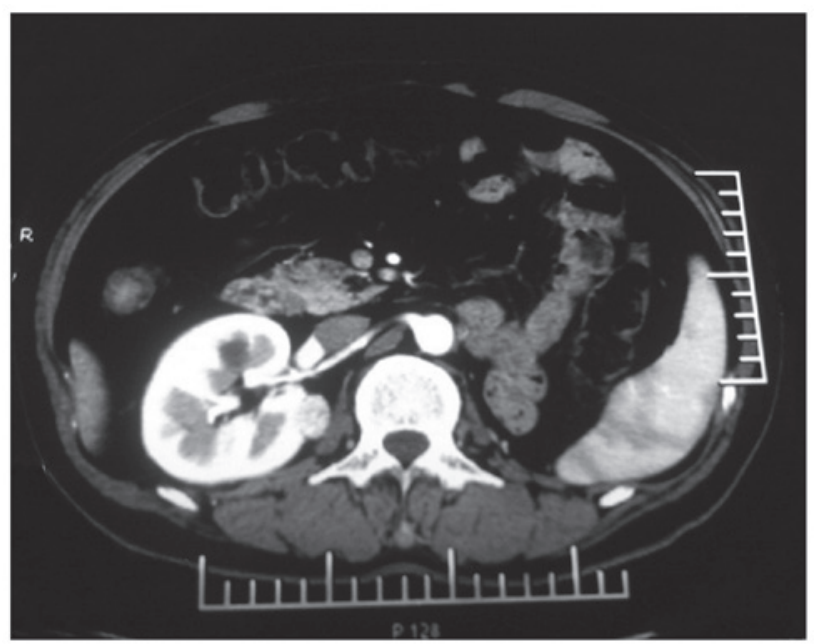

Figure 8.Computed tomography scan detected multiple solid space-occupying lesions in the right kidney.

regularly reviewed following surgery. However, 1 year later, CT scanning detected multiple solid space-occupying lesions in the right kidney (Fig. 8). Consequently, the patient was treated with first-line sunitinib targeted therapy.

At present, the patient is generally in good condition, without obvious drug side effects and discomfort complaint.

\section{Discussion}

RCC possesses a propensity for distal metastasis, which may occur in all organs, including the lung, lymph node, liver and bone. However, RCC rarely metastasizes to the adrenal gland and urinary bladder $(4,11)$. In a previous study of $>400$ patients who had undergone radical nephrectomy for RCC, isolated contralateral adrenal gland metastases accounted for $2.5 \%$ of the total cases $(6,12)$. Additionally, Saitoh et al (13) reported $1.6 \%$ of clinically detectable bladder metastases in 1,451 autopsy cases of patients with $\operatorname{RCC}(5,6,12,14)$.
Nonetheless, ccRCC with metachronous metastasis to the contralateral adrenal gland and urinary bladder has not been reported thus far.

Contralateral adrenal gland metastasis is hypothesized to develop through the hematogenous route. Dieckmann et al (15) suggested that the adrenal gland may act as 'fertile soil' and 'raise' the seeding tumor cells from the contralateral primary RCC, since the adrenal gland exhibits high affinity for metastases of RCC $(15,16)$. The mechanism by which RCC metastasizes to the urinary bladder remains unclear, although it has been suggested to occur via the hematogenous route, lymphatic system or urinary stream (5). The hematogenous metastasis pathway may occur through the systemic circulation or through retrograde venous dissemination, such as via the gonadal and ureteral vein, when the renal vein is obstructed by cancer emboli (14). When a tumor invades the kidney pelvis, or following diagnostic biopsy using an ureteroscope, it may metastasize via the urinary stream (5). Additionally, direct extension and seeding implantation have been proposed as potential mechanisms for metastasis of $\mathrm{RCC}$, since cancer cells have been detected in the urine of patients with RCC (17).

Patients with distal metastases present a worse prognosis than those without metastatic tumors, with a 5-year survival rate of $<10 \%$ (11), although radical nephrectomy and resection of a single or limited metastases may prolong the survival rate by $30 \%$ (6). Patients with metastatic RCC may benefit from minimal invasive surgeries, such as laparoscopic and endoscopic resection of metastatic neoplasms from RCC (6). However, depending on the tumor size and the strength of the adhesion to the peripheral organs, minimal invasive surgeries may not always be possible to perform. Surgical treatments rarely present complications, and should be recommended in all cases of RCC for a curative outcome (18). Despite the fact that the majority of patients with RCC that had undergone surgery succumbed as a result of RCC, their survival time was longer than those who had not undergone surgical treatment (6).

In a randomized phase III trial, Motzer et al (19) reported that the median progression-free survival of patients treated with sunitinib was 11 months. In the present case, the patient experienced metastasis of RCC to the contralateral kidney following resection of the adrenal gland and urinary bladder tumor. Therefore, the patient was advised to receive first-line sunitinib targeted therapy, which is known to be an effective treatment for metastatic RCC (20). To date, the patient is generally in good condition, without any evidence of drug side effects or complaints of discomfort.

\section{References}

1. Choi JB, Yoon BI, Kim SJ, Cho HJ, Hong SH, Choi YJ, Kim SW, Hwang TK and Lee JY: Changes in clinicopathological characteristics of renal cell carcinoma in the past 25 years: A single-center experience. Korean J Urol 52: 110-114, 2011.

2. Siegel R, Naishadham D and Jemal A: Cancer statistics. CA Cancer J Clin 63: 11-30, 2013.

3. Melegari S, Albo G, Rocco B, Verweij F, Abbinante M and de Cobelli O: Metachronous bladder metastases from renal cell carcinoma: A case report and review of the literature. Ecancermedicalscience 4: 175, 2010. 
4. Chung PH, Srinivasan R, Linehan WM, Pinto PA and Bratslavsky G: Renal cell carcinoma with metastases to the gallbladder: Four cases from the National Cancer Institute (NCI) and review of the literature. Urol Oncol 30: 476-481, 2012.

5. Kagota M, Irie K, Hosaka K and Takezaki T: Bladder metastasis of renal cell carcinoma; a case study. Hinyokika Kiyo 53: 571-574, 2007

6. Lau WK, Zincke H, Lohse CM, Cheville JC, Weaver AL and Blute ML: Contralateral adrenal metastasis of renal cell carcinoma: Treatment, outcome and a review. BJU Int 91:775-779, 2003.

7. Brinkmann OA, Semik M and Gosherger G: The role of residual tumor resection in patients with metastatic renal cell carcinoma and partial remission following immunotherapy. Eur Urol 6: 641-645, 2007.

8. Alt AL, Bllrjian SA, Lohse CM Costello BA, Leibovich BC and Blute ML: Survival after complete surgical resection of multiple metastases from renal cell carcinoma. Cancer 117: 2873-2882, 2011.

9. Kwak C,Park YH, Jeong CW, Lee SE and Ku JH: Metastasectomy without systemic therapy in metastatic renal cell carcinoma: Comparison with conservative treatment. Urol Int 79: 145-151, 2007.

10. Martínez-Salamanca JI, Huang WC, Millán I, Bertini R, Bianco FJ, Carballido JA, Ciancio G, Hernández C, Herranz F, Haferkamp A, et al; International Renal Cell Carcinoma-Venous Thrombus Consortium: Prognostic impact of the 2009 UICC/ AJCC TNM staging system for renal cell carcinoma with venous extension. Eur Urol 59: 120-127, 2011.

11. Shoji S, Mukai M, Yazawa N, Sekido Y, Nagata Y, Uchida T and Terachi T: Metastasis to gallbladder and adrenal gland of renal cell carcinoma. Oncol Lett 1: 507-509, 2010.
12. Moslemi MK, Saghafi H and Firoozabadi MH: Renal cell carcinoma with simultaneous bilateral adrenal metastasis: Ipsilateral radical nephrectomy with contralateral adrenal preservation. Case Rep Oncol 3: 372-379, 2010.

13. Saitoh H: Distant metastasis of renal cell adenocarcinoma Cancer 48: 1487-1491, 1981

14. Shiraishi K, Mohri J, Inoue R and Kamiryo Y: Metastatic renal cell carcinoma to the bladder 12 years after radical nephrectomy. Int J Urol 10: 453-455, 2003.

15. Dieckmann KP, Wullbrand A and Krolzig G: Contralateral adrenal metastasis in renal cell cancer. Scand J Urol Nephrol 30: 139-143, 1996.

16. Sagalowsky AI, Kadesky KT, Ewalt DM and Kennedy TJ: Factors influencing adrenal metastasis in renal cell carcinoma. J Urol 151: 1181-1184, 1994.

17. Joshi DP, Shah RB, Montie JE and Lee CT: Isolated recurrent renal cell carcinoma metastatic to the bladder. J Natl Med Assoc 94: 912-914, 2002.

18. Utsumi T, Suzuki H, Nakamura K, Kim W, Kamijima S, Awa Y, Araki K, Nihei N, Naya Y and Ichikawa T: Renal cell carcinoma with a huge solitary metastasis to the contralateral adrenal gland: A case report. Int J Urol 15: 1077-1079, 2008.

19. Motzer RJ, Hutson TE, Tomczak P, Michaelson MD, Bukowski RM, Oudard S, Negrier S, Szczylik C, Pili R, Bjarnason GA, et al: Overall survival and updated results for sunitinib compared with interferon alfa in patients with metastatic renal cell carcinoma. J Clin Oncol 27: 3584-3590, 2009.

20. Coppin C, Kollmannsberger C, Le L, Porzsolt F and Wilt TJ: Targeted therapy for advanced renal cell cancer (RCC): A Cochrane systematic review of published randomised trials. BJU Int 108: 1556-1563, 2011. 